\title{
It's Just Emotion Taking Me Over: Investigating the Role of Emotions in Knowledge Management Research
}

\author{
Olivia Hornung \\ University of Hagen, Germany \\ olivia.hornung@fernuni-hagen.de
}

\author{
Stefan Smolnik \\ University of Hagen, Germany \\ stefan.smolnik@fernuni-hagen.de
}

\begin{abstract}
The importance of emotions has increasingly been recognized in the information systems field. Emotions do not only influence the human mind, but can also be transferred to others through knowledge. This transfer of knowledge is part of the broader organizational concept of knowledge management (KM) and requires the attention of researchers interested in emotions and emotion theories. Therefore, our paper presents a systematic review of existing evidence on the emotions' role in KM research. Our review shows that despite KM's long tradition, there is only limited evidence as to how emotions are related to KM, most of which mention emotions as motivation for KM. As a result of our study, we identify four research opportunities to further examine certain aspects of emotions' role in $\mathrm{KM}$.
\end{abstract}

\section{Introduction}

Originally emerged from the disciplines of economics, sociology, and psychology [54], the field of knowledge management (KM) and its different aspects have been researched by the information systems (IS) discipline for many years now [66]. Topics investigated range from knowledge and KM definitions, theories and technologies [31, 72] to knowledge types, KM processes, as well as managerial issues regarding $\mathrm{KM}$ [18].

$\mathrm{KM}$ has shown to have a positive effect on employees' work performance and productivity through the encouragement of interaction and collaboration [6, 77]. Hence, it can be a valuable contributor to organizational success. However, due to knowledge being composed of experience, values, and information [11], it clearly includes human additions and is context-specific [45]. Therefore, it can be problematic and counterproductive when organizations merely view knowledge as another asset they can activate and manage without accounting for its origin and special characteristics.

Just like knowledge being unconditionally attached to humans, emotions are inseparable of human action and "there is no action without affect" [26]. Transferring knowledge is not free of value as it is tied to the knowledge carrier's emotions [3], and exactly those emotions such as anticipation, trust, or apprehension enable others to make sense of someone else's knowledge [11]. Furthermore, emotions are the primary motivational system for humans [36, 43] and are thus inevitably a key component of the human experience interacting with other humans or objects such as IS [46]. The interweaving of emotions and knowledge as well as emotions as primary motivation for action make research on emotion's role in KM intriguing. Albeit there having been some research on the role of emotions and the existence of an emotional component in tacit knowledge and how it can benefit or harm KM [32, 55], there is no systematic literature review on previous research connecting emotions and $\mathrm{KM}$, making research in this field incomplete. The relationship between KM and emotions promises to be so rich that a literature review could be a first step towards further exploring this relationship and field of study and identifying under-researched areas.

In this study, we aim at presenting the state-of-theart of research regarding the emotions' role in KM research by reviewing previous research that mention such ties. We chose to include all types of studies, whether based on literature or empirical data that provide all kinds of insights for our topic. Furthermore, we examine how emotions are conceptualized in these studies. Therefore, we derive the following research question:

How is the role of emotions displayed in previous KM research?

By answering this research question, we aim to identify research opportunities for future KM research on emotions as well showing previous emphases in KM research regarding the emotions' role. Thereby, we contribute to research by exposing research gaps which may serve as a source for inspiration regarding future research undertakings. Furthermore, by contributing to research within the KM discipline, we ultimately also contribute to IS research that deals with emotions' influence on IS. 


\section{Theoretical background}

\subsection{Emotions}

The concept of emotion has been recognized and conceptualized within the psychology discipline early on. While there have been researchers that have stated emotions would be virtually impossible to define without conflicting theories [15], going as far as declaring that the disagreement over definitions has even stood in the way of finding an acceptable theory of emotions [8]. Nonetheless, researchers of all domains, starting with psychology, but also sociology and economics, have tried providing definitions and theories of emotion. One of the oldest and most popular definitions has been provided by Leeper [36], who states that emotions are primarily motivating forces; they are "processes which arouse, sustain, and direct activity" (p. 17). Other authors generalize his idea and declare that emotions are directing cognitive activities [9, 40]. As research progressed, the definitions became more precise, seeing emotions as specific neuropsychological phenomena which are shaped by natural selection to organize and motivate physiological, cognitive, and action patterns [25] or as "an inferred complex sequence of reactions to a stimulus" [52]. We will use the definition provided by Salovey and Mayer given in the context of research on emotion-related skills. They state that emotions can be seen as organized responses that cross the boundaries of many psychological subsystems, typically in response to an internal or external event, which has been assessed as positive or negative for the individual [58].

Even though there are definitions and conceptualizations of emotions, there has been much confusion as to whether the commonly used synonyms for emotion, such as mood, feeling, and perception, really are the same as emotion or are falsely used in a synonymous manner. Research suggests that emotions and moods are related but distinct phenomena [4]. Also, there is a difference between mood and emotion in which the latter are shorter and generally more intense [58], albeit they both are cognitive elements that humans can distinguish from purely physical sensations [17]. Perception, however, incorporates these physical sensations as it can be defined as recognizing and interpreting sensory information [59]. Nonetheless, this distinction has not always been and is still not made in some research - possibly due to the vast array of possible definitions. Therefore, we will search for all three terms (emotion, mood, and feeling) in order not to exclude relevant research.

\subsection{Knowledge management}

Since the mid-1990s, KM has become more important and popular as a business initiative as well as a research topic, growing into an established discipline with its own journals, embedded in the midst of the IS domain [28]. As mentioned, knowledge is a blend of experience, values, and information, oftentimes found embedded in documents, repositories, and routines as well as processes and norms within organizations [11]. In order to find meaning in knowledge, one must understand and be experienced regarding the context and surrounding conditions prevailing during generation and use of knowledge [28].

There are several knowledge taxonomies, of which the most popular in research are [63] Polyani's [53] and Nonaka's [45] taxonomies which differentiate between tacit and explicit knowledge. Explicit knowledge generally refers to codified knowledge, possibly found in documents or other media. Tacit knowledge is much harder to grasp as it is not codified and usually personal and experience-based. Thus, only attempts of expressing and documenting tacit knowledge can be made.

Both types of knowledge constitute an important organizational asset. Hence, the discipline of KM was born. KM is an organization's systematic and conscious effort to enhance, maintain and use knowledge in a value-adding manner to fulfill tasks and improve the organization's position [24]. These efforts are often pursued with the help of KM systems (KMS) - even though KM is not purely technical in nature [28].

\subsection{An emotions-in-KM framework}

Emotions can be seen as a chronologically unfolding sequence with someone being exposed to a stimulus, experiences a state of "feeling" with consequences leading to externally visible behaviors and outputs which, in turn, become input for interaction partners [14].

Just like emotions, knowledge is not an object, but rather a process [69]. And just like emotions and knowledge, $\mathrm{KM}$ also follows a sequence that unfolds chronologically and can be observed from several perspectives. Researchers have previously often investigated the relationship between the KM factors enablers, processes, and performance [34]. Thus, we will apply a simple input-process-output model to structure our literature review [16]. The advantage of such a model is that it separates the KM processes 
from the motivation as input requirement as well as $\mathrm{KM}$ success as an output for the environment.

Input can be of tangible as well as intangible nature. In order for any KM process to be triggered, an employee has to be motivated to start it - thus making motivation our starting point. Processes can be any type of process related to knowledge management, such as Alavi and Leidner's processes of knowledge creation, storage and retrieval, transfer, as well as application [2] or Davenport and Prusak's processes of knowledge generation, codification and coordination, and transfer [11]. The goal of any given $K M$ process is to contribute towards a greater goal, which we call $K M$ success. Success can be the "creation" (explication or codification) of new knowledge or simply "capturing the right knowledge, getting the right knowledge to the right user, and using this knowledge to improve organizational and/or individual performance” [30].

Emotions as the overarching concept can potentially influence any step of the KM sequence. Therefore, we propose the framework presented in Figure 1 to logically cluster the literature we analyze.

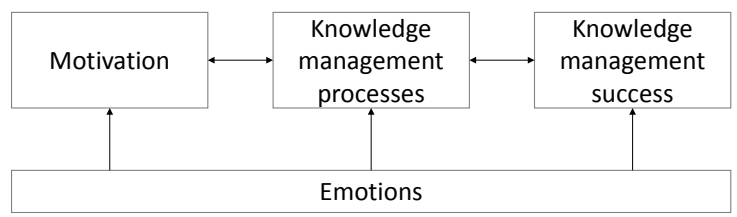

Figure 1. Emotions-in-KM framework

\section{Research process and method}

We base our study on the recommendations of Webster and Watson for conducting a comprehensive structured literature review [79]. Thus, we first conducted our search in the leading journals of the IS domain which belong to the Senior Scholars' Basket of Journals comprising the discipline's major contributions [79].

Since the goal of this literature is to identify the state-of-the-art concerning research on KM and emotions, we decided not to limit our search to the Senior Scholars' Basket of Journals, but expand our sample including the leading $\mathrm{KM}$ journals rated $\mathrm{A}+$ and A in the latest update of Serenko's and Bontis' global ranking of knowledge management and intellectual capital academic journals [65]. These six journals are the Journal of Knowledge Management, the Journal of Intellectual Capital, The Learning Organization, Knowledge Management Research \& Practice, Knowledge and Process Management: The Journal of Corporate Transformation, and the International Journal of Knowledge Management.
Additionally, we supplemented our findings by adding the proceedings of the five leading international IS conferences in our literature review, these being the International Conference on Information Systems (ICIS), the European Conference on Information Systems (ECIS), the Hawaii International Conference on System Sciences (HICSS), the Americas Conference on Information Systems (AMCIS), as well as the Pacific Asia Conference on Information Systems (PACIS). Wherever possible, we searched literature through the EBSCOhost or ScienceDirect databases as well as the Association for Information Systems (AIS) eLibrary. If publications were not available in these databases, we directly searched the respective websites. Due to resource and time constraints, we decided to not further extend the sample as we deemed the incorporated fourteen journals and five conference proceedings to be sufficient for our exploratory study.

Where possible, we searched within the metadata, more specifically the title, keywords, or abstract for the words emotion (emoti*), mood, or feeling (feel*) in combination with "knowledge management." For the KM journals, we omitted searching for "knowledge management" as the thematic focus of these journals already requires a KM context. Whenever a journal did not allow a search within title, keywords, and abstract, but only a full-text search, we manually screened the metadata for our search items. We did not limit the search to any specific time period as we wanted to capture all papers since the emergence of the term "knowledge management" in IS research. Our search left us with a total of 39 publications matching the criteria, of which we omitted seven papers due to not using emotions, moods, or feelings as a part of their research, but rather as an aspect of the English language's vocabulary.

As seen in Table 1, the final sample are 32 papers.

\section{Table 1. Literature sources and number of included papers}

\begin{tabular}{|l|c|}
\hline Journal / conference proceeding & Final sample \\
\hline $\begin{array}{l}\text { European Journal of Information } \\
\text { Systems }\end{array}$ & 0 \\
\hline Information Systems Journal & 0 \\
\hline Information Systems Research & 0 \\
\hline $\begin{array}{l}\text { Journal of the Association for } \\
\text { Information Systems }\end{array}$ & 1 \\
\hline $\begin{array}{l}\text { Journal of Information } \\
\text { Technology }\end{array}$ & 0 \\
\hline $\begin{array}{l}\text { Journal of Management } \\
\text { Information Systems }\end{array}$ & 1 \\
\hline $\begin{array}{l}\text { Journal of Strategic Information } \\
\text { Systems }\end{array}$ & 0 \\
\hline
\end{tabular}




\begin{tabular}{|l|c|}
\hline MIS Quarterly & 0 \\
\hline $\begin{array}{l}\text { Journal of Knowledge } \\
\text { Management }\end{array}$ & 4 \\
\hline Journal of Intellectual Capital & 1 \\
\hline The Learning Organization & 3 \\
\hline $\begin{array}{l}\text { Knowledge Management } \\
\text { Research \& Practice }\end{array}$ & 2 \\
\hline $\begin{array}{l}\text { Knowledge and Process } \\
\text { Management: The Journal of } \\
\text { Corporate Transformation }\end{array}$ & 0 \\
\hline $\begin{array}{l}\text { International Journal of } \\
\text { Knowledge Management }\end{array}$ & 1 \\
\hline $\begin{array}{l}\text { International Conference on } \\
\text { Information Systems (ICIS) }\end{array}$ & 5 \\
\hline $\begin{array}{l}\text { European Conference on } \\
\text { Information Systems (ECIS) }\end{array}$ & 1 \\
\hline $\begin{array}{l}\text { Hawaii International Conference } \\
\text { on System Sciences (HICSS) }\end{array}$ & $\mathbf{3 2}$ \\
\hline $\begin{array}{l}\text { Americas Conference on } \\
\text { Information Systems (AMCIS) }\end{array}$ & TOTAL \\
\hline $\begin{array}{l}\text { Pacific Asia Conference on } \\
\text { Information Systems (PACIS) }\end{array}$ & \multicolumn{1}{|c|}{} \\
\hline
\end{tabular}

The timeline in Figure 2 categorizes the findings according to publication year. Here, it can be seen that the sparse findings before 2006 indicate a lack of interest in the topic of emotions in the realm of KM. Despite there not being a consistent increase in publications, there is a clear rise in interest of this topic, especially after 2011.

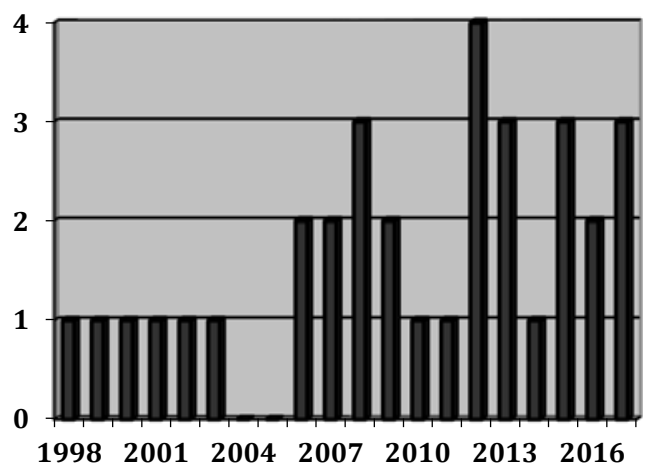

Figure 2. Number of publications found according to publication year

A vast majority of 23 publications incorporate some type of empirical data. Research methods within the sample vary but are almost evenly distributed between qualitative and quantitative methods, as Figure 3 shows. The category 'other' includes editorials as well types of publications uncommon in
IS literature, such as a historical analysis conducted by Davern et al. [12].

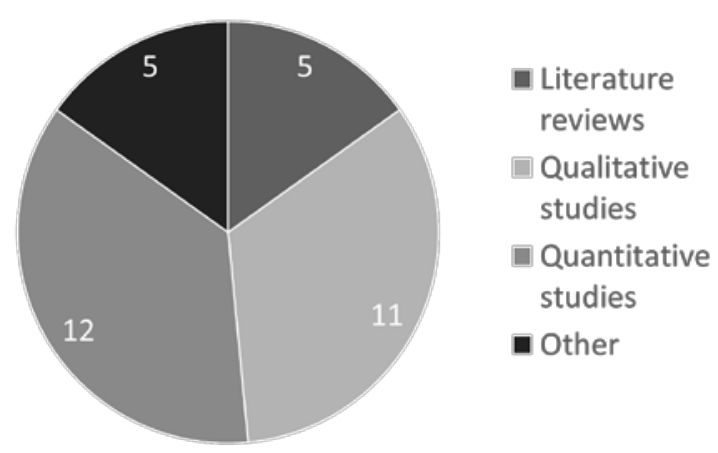

Figure 3. Type of publications found according to data type

Figure 4 shows the results of our analysis according to the emotions-in-KM framework presented in section 2.3. The numbers in the figure represent the amount of studies which have declared emotions as the motivation or part of the motivation for conducting $\mathrm{KM}$ processes, as a direct occurrence during $\mathrm{KM}$ processes, or as outcomes of the $\mathrm{KM}$ process, in which case they serve as measure for KM success or failure.

The final sample comprises 22 papers treating emotions and emotive concepts as motivation, four papers showing emotions directly in KM processes, and six declaring emotions to be part of KM success.

\begin{tabular}{|c|c|c|}
\hline Motivation & $\begin{array}{c}\text { Knowledge } \\
\text { management } \\
\text { processes }\end{array}$ & $\begin{array}{c}\text { Knowledge } \\
\text { management } \\
\text { success }\end{array}$ \\
\hline 22 & 4 & 6 \\
\hline \multicolumn{3}{|c|}{ Emotions } \\
\hline
\end{tabular}

Figure 4. Results of the analysis of the selected literature

\section{Findings}

\subsection{Emotions as motivation}

The first step of our content analysis was to review the final sample for studies conceptualizing emotions and emotive variables as motivators for behavior, more specifically as motivators for the use or non-use of $\mathrm{KM}$ processes. A vast majority, in particular 22 of the 32 included publications, regards emotions as a motivational force for KM. 
The analysis reveals that there are researchers making out a strong case for $\mathrm{KM}$, finding that amongst different qualities of mind that organizations can develop, emotions are of high value as they expand learning capacities [41]. They also argue that emotions are seen as part of the mindset and KMS need to be designed appropriately in order to foster emotions [67], especially when organizational changes occur [56]. Moreover, emotions are part of the organizational culture [21], and welcoming new employees emotionally will help significantly in turning them into valuable KM contributors [57], making it fatal to ignore emotions' importance.

Several researchers agree that while dealing with emotions is inevitable, there are hindrances as it can be problematic and precarious to actively manage KM-motivation-related emotions [19], especially since emotional containment has an impact on knowledge creation [48]. Particularly, feeling incompetent leads to avoidance of KM as well as KMS use [37].

We also reviewed publications that use a specific emotional theory or emotive concepts as an influential factor: Tuan argues that emotional intelligence can strongly trigger collective KM processes by causing competitive intelligence and, in turn, influence the motivation to use KM resources and processes [75, 76]. Decker et al. even discovered that there are noteworthy relationships between emotional intelligence and knowledge transfer, not only regarding the willingness to transfer knowledge, but also the variety of methods used to transfer knowledge [13].

Furthermore, basing their research on knowledge hiding, de Geofroy and Evans come to the conclusion that high emotional intelligence in employees decreases knowledge hiding [20] while Peng finds that strong psychological ownership feelings lead to knowledge hiding [49].

Further concepts are the concept of emotive knowledge, presented by Schiuma and Lerro, as the driver and key factor for employee engagement in creation of knowledge and other intangible value [62], and also reinforcing the confidence in social power [35] as well as information use and valuation [23].

Malhotra et al. study endogenous motivations influencing user intention of KMS and find that user intentions can best be predicted and explained through feelings [39]. Van den Hooff et al. operate with more specific emotions, investigating which emotions most influence attitudes and intentions towards knowledge sharing and find that pride and empathy influence KM attitude [78]. Linden even calls this pride a "heroic mood" [38]. Swift and Hwang promote the role of affective, meaning emotional, trust as a booster for knowledge sharing between executives, which in turn established a good organizational learning climate [70]. Song and Teng specify the role of trust for KM as they find that the feeling of solidarity increases voluntary knowledge sharing [68].

Overall, it becomes clear that emotions can generally be classified as "positive emotions" increase the motivation for KM use [71]. Figure 5 summarizes the analysis' results according to the different clusters of emotive concepts, consisting of emotional intelligence and emotive knowledge, hindrances, such as emotional containment and emotion management, and specific emotions, namely emotional trust, pride and empathy as well as feelings of solidarity. The arrows in Figure 5 represent contribution. Different aspects contribute to a cluster. In turn, the three clusters, namely emotive concepts, hindrances and specific emotions, all contribute to motivation.

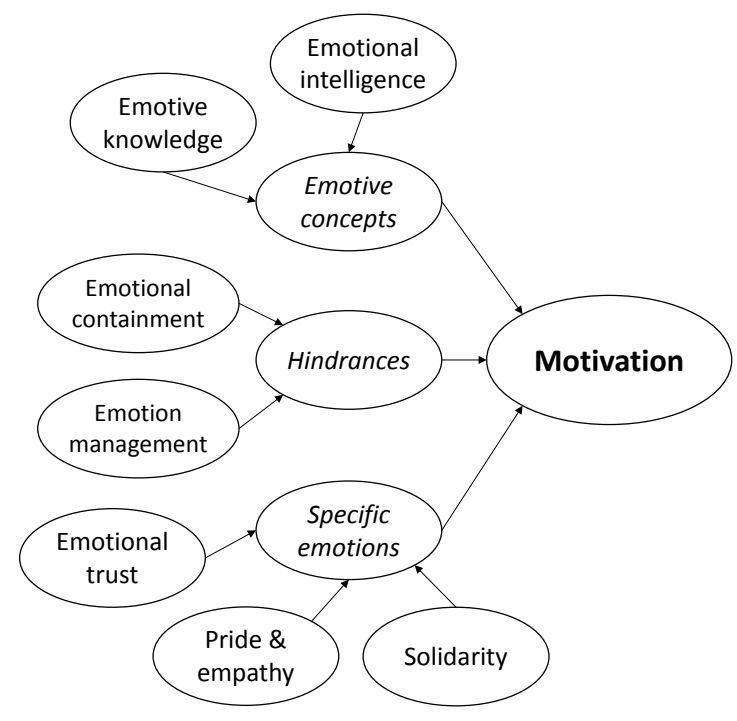

Figure 5. Results of the selected literature regarding motivation

\subsection{Emotions in the KM process}

The second step of our content analysis was to review the final sample for studies showing emotions and emotive variables directly in KM processes, more specifically as occurrence within KM processes in general as well as specific KM processes. A small part, in particular four of the 32 included publications, addresses emotions in KM processes.

Firstly, Davern et al. argue that emotive designs in IS, such as KM processes and KMS for decision support, are starting to become the norm [12]. The concept of emotive knowledge again emerges here with specific regard to the tacit knowledge conversion process, as emotive knowledge strongly impacts it [5]. 
In her research, Hafner refers to a two-sided theory of technological upset versus technological ease during unlearning, an important concept and specific kind of knowledge acquisition [22]. Different than Hafner, Aarrestad et al. do not specify a type of emotion, but rather focus on the process of knowledge creation and find that the emotional intensity occurring during knowledge creation leads to intensified collaboration in high-quality connections [1].

Due to the low number of papers specifying emotions as an occurrence during the KM process or focusing specifically on the KM process, we could not cluster these publications.

\subsection{Emotions as part of KM success}

The third and last step of our content analysis was to review the final sample for studies conceptualizing emotions and emotive variables as outcomes of KM processes, more specifically as indicators for $\mathrm{KM}$ success. A small part, in particular six of the 32 included publications, regards emotions as an outcome and indicator for success.

Most publications in this section clearly indicate that the emotional outputs created through the KM process(es) can clearly be seen as positive and, thus, contributing to KM success. Von der Trenck et al. state that there are massive emotional benefits from knowledge sharing which strongly increase the employees perceived value of knowledge sharing [74]. Öztel and Hinz come to the conclusion that metaphors, which are often particularly used as a way of transferring tacit knowledge, create emotions [47]. Only Caya et al. have a critical view on KM processes and believe that team arousal and stress can be a negative outcome of $\mathrm{KM}$, lowering performance of business process teams and preventing KM success [7].

We also reviewed publications that use a specific emotional theory or emotive concepts as an influential factor: An emotional epiphany can be an indicator for $\mathrm{KM}$ success and the acknowledgement that an employee or a team created something new through the combination of knowledge and capabilities [44]. A concept called emotional connectedness can be leveraged through the willingness to implement "soft" change and KM processes, especially knowledge transfer [33]. This emotional connectedness is seen as a highly desirable outcome of KM as it ultimately can be viewed as a measure of successful KM. Furthermore, Tran views emotional climate as a success factor, which is of utmost importance for a learning organization [73] and also represents a dimension of KM success.
As for emotions in $\mathrm{KM}$ processes, we could not cluster the previous publications due to the low number of papers specifying emotions as outcome or part of KM success.

\section{Research opportunities}

Overall, the findings of our literature analysis reveal that the vast majority of research on the relationship between emotions and KM mention emotions as motivation for KM use or non-use. But especially emotions as a result of motivation and KM processes - as part of KM success - are underresearched and constitute an interesting future research endeavor. Oftentimes, KM is mistaken for KMS only, but to succeed, it is vital that KM is approach as an organizational task and not a technical one [27]. Scherer and Tran suggest that careful consideration has to be given to the different potential emotional effects and outcomes [61]. Therefore, future research could focus on emotions as KM outcome and contributor to KM success (RO1).

Some studies in each part of our framework already focus on specific emotions, both positive and negative. Narrowing down a research endeavor to a specific emotion could deepen and specify the results. Taxonomies of emotions which could be used are Plutchik's emotional profile index [51], Scherer's wheel of emotion [60], or Izard's differential emotion scale [26]. Using such an analytical framework captures as much as possible of emotions [42]. Consequently, a second research opportunity could be to examine a chosen emotion or particular set of emotions and their role within KM (RO2).

Some studies in our sample have referred to the concept of emotive knowledge, both as motivation [62] and occurrence during the KM process [5]. Drawing on the concept of bounded rationality, negative emotions, such as anger, direct human attention towards a very small number of alternatives, making it unlikely that an employee will make a decision that will advance the organization [64], e.g. sharing tacit or emotive knowledge or using knowledge associated with the source of the negative emotions. Additionally, emotive knowledge is especially difficult to obtain since it can hardly be obtained by threat or punishment, but has to be voluntarily shared [29] resting upon intrinsic motivation [10]. Thus, future research could focus on emotive knowledge and which specific emotions support or hinder the creation and use of it (RO3).

Finally, emotional intelligence as a recurring concept in the findings of our literature review, deserves more attention, especially as outcome of successfully passed KM processes. Emotional 
intelligence is a common indicator for high motivation towards KM use and other KM processes [13, 20]. Even in its original form, consisting of appraisal and expression of emotion, use of emotion and regulation of emotion [58], it would be an interesting research subject - testing if KM processes result in emotional intelligence. A more recent taxonomy of emotional intelligence considers adaptability, assertiveness, emotion appraisal, emotion expression, emotion management, emotion regulation, low impulsiveness, relationship skills, self-esteem, self-motivation, social competence, stress management, trait empathy, trait happiness, and trait optimism [50]. Going into this detail, it could be intriguing to find out which of these traits can be established or improved through KM. Thus, researchers could test whether KM can enhance or improve emotional intelligence (RO4).

Table 2. Research opportunities' overview

\begin{tabular}{|c|c|}
\hline $\begin{array}{l}\text { Research } \\
\text { opportunity }\end{array}$ & Description \\
\hline RO1 & $\begin{array}{l}\text { Future research could focus on } \\
\text { emotions as KM outcome and } \\
\text { contributor to KM success. }\end{array}$ \\
\hline $\mathrm{RO} 2$ & $\begin{array}{l}\text { Research could be to examine a } \\
\text { chosen emotion or particular set of } \\
\text { emotions and their role within KM. }\end{array}$ \\
\hline $\mathrm{RO} 3$ & $\begin{array}{l}\text { Future research could focus on } \\
\text { emotive knowledge and which } \\
\text { specific emotions support or hinder } \\
\text { the creation and use of it. }\end{array}$ \\
\hline RO4 & $\begin{array}{l}\text { Researchers could test whether KM } \\
\text { can enhance or improve emotional } \\
\text { intelligence. }\end{array}$ \\
\hline
\end{tabular}

\section{Conclusion}

In our study, we performed a structured literature review of the emotions' role in KM research. We recognized and incorporated an emotion-in-KM framework, dividing KM into motivation, processes, and success, and connected emotions with each of these parts. To fulfill our aim of giving a comprehensive overview of emotions in $\mathrm{KM}$, we searched for all types of publications in the leading journals and conferences of the IS research field as well as the leading journals of the KM discipline.

During our study, we identified 32 relevant research papers of over 1,000 initial hits, which were due to most journals lacking a search function for metadata such as abstract, title, and keywords, making an ample manual screening process necessary. Furthermore, we analyzed and assigned these publications to our initially developed review framework. As a result, we identified four research opportunities.

In our findings, it becomes clear that the focus of previous research has been on emotions and motivation for KM. We found very little research emotions in KM processes or as part of KM success. Thus, our research opportunities suggest that emotions as outcome and part of KM success could be investigated in further research endeavors. We also believe research regarding a chosen emotion or particular set of emotions and their role in the realm of KM would enrich the topic. Furthermore, we show that research could be done regarding the emotional concepts of emotive knowledge, and which specific emotions support or hinder the creation and use of it, as well as emotional intelligence, and whether KM can enhance or improve it.

Some limitations of our research should be considered. Biases might occur in our review due to our choice of keywords and the inclusion of only leading IS journals and conference proceedings as well as leading KM journals, and the subjective influences possibly effecting the selection and classification of incorporated studies. Other researchers could possibly have undertaken a different selection and classification of studies. Additionally, we also included papers about moods and feelings in addition to publications explicitly dealing with emotions. As discussed in section 2.1, these concepts are not the same, but often used synonymously, which is why omitting them would suggest an incomplete picture of the chosen topic.

In order to improve and extend the significance of our results, all major databases could be searched in order to conduct a more comprehensive literature review. Nonetheless, we have faith that our results are replicable and would successfully withstand an extended literature review.

Finally, our research accounts for several contributions to the theoretical body of knowledge. This is the first effort of a structured literature review and analysis concerning the emotions' role in KM research to the best of our knowledge and belief. Besides, we exposed several research opportunities which can inspire other IS researchers to undertake research concerning emotions and KM. Additionally, by contributing to research within the KM discipline, we ultimately also contribute to IS research that deals with the influence of emotions on IS.

\section{References}

[1] Aarrestad, M., M.T. Brøndbo, and A. Carlsen, "When Stakes are High and Guards are Low: High-quality 
Connections in Knowledge Creation”, Knowledge and Process Management, 22(2), 2015, pp. 88-98.

[2] Alavi, M. and D.E. Leidner, "Review: Knowledge Management and Knowledge Management Systems: Conceptual Foundations and Research Issues”, MIS Quarterly, 25(1), 2001, p. 107.

[3] Aldrich, H., Organizations evolving, Sage, London, 1999.

[4] Beedie, C., P. Terry, and A. Lane, "Distinctions between emotion and mood”, Cognition \& Emotion, 19(6), 2005, pp. 847-878.

[5] Byosiere, P. and D.J. Luethge, "Knowledge domains and knowledge conversion: An empirical investigation”, Journal of Knowledge Management, 12(2), 2008, pp. 6778.

[6] Cao, X., D.R. Vogel, X. Guo, H. Liu, and J. Gu, "Understanding the Influence of Social Media in the Workplace: An Integration of Media Synchronicity and Social Capital Theories", in $201245^{\text {th }}$ Hawaii International Conference on System Science: (HICSS) ; USA, 4 - 7 Jan. 2012, R.H. Sprague, Editor, $201245^{\text {th }}$ Hawaii International Conference on System Sciences (HICSS), Maui, HI, USA, 4/1/2012 - 7/1/2012. 2012. IEEE: Piscataway, NJ.

[7] Caya, O., É. Brunelle, P.-M. Leger, and T. Grebot, “An Empirical Study on Emotions, Knowledge Management Processes, and Performance within Integrated Business Process Teams”, in 2012 45 $5^{\text {th }}$ Hawaii International Conference on System Science: (HICSS) ; USA, 4 - 7 Jan. 2012, R.H. Sprague, Editor, 2012 45 ${ }^{\text {th }}$ Hawaii International Conference on System Sciences (HICSS), Maui, HI, USA, 4/1/2012 - 7/1/2012. 2012. IEEE: Piscataway, NJ.

[8] Chaplin, J.S. and T.S. Krawiec, "SYSTEMS AND THEORIES OF PSYCHOLOGY”, University of Illinois Press, Champaign, IL, 1979.

[9] Clark, M.S. and S.T. Fiske, Affect and cognition: The seventeenth annual Carnegie symposium on cognition, Psychology Press, 1982.

[10] Csikszentmihalyi, M., Flow: The psychology of optimal performance, Harper\&Row, New York, 1990.

[11] Davenport, T.H. and L. Prusak, Working knowledge: How organizations manage what they know, Harvard Business Press, 1998.

[12] Davern, M., T. Shaft, and D. Te'eni, “Cognition Matters: Enduring Questions in Cognitive IS Research”, Journal of the Association for Information Systems, 13(4), 2012, pp. 273-314.

[13] Decker, B., R.E. Landaeta, and T.G. Kotnour, "Exploring the relationships between emotional intelligence and the use of knowledge transfer methods in the project environment”, Knowledge Management Research \& Practice, 7(1), 2009, pp. 15-36.

[14] Elfenbein, H.A., "Emotion in Organizations", The Academy of Management Annals, 1(1), 2007, pp. 315-386.
[15] English, H.B. and A.C. English, “A comprehensive dictionary of psychological and psychoanalytical terms: A guide to usage”, Longmans, Green, 1958.

[16] Fedor, D.B., S. Ghosh, S.D. Caldwell, T.J. Maurer, and V.R. Singhal, "The Effects of Knowledge Management on Team Members' Ratings of Project Success and Impact*”, Decision Sciences, 34(3), 2003, pp. 513-539.

[17] Fredrickson, B.L. and T. Joiner, "Positive Emotions Trigger Upward Spirals Toward Emotional Well-Being”, Psychological Science, 13(2), 2002, pp. 172-175.

[18] Fteimi, N. and F. Lehner, "Main Research Topics in Knowledge Management: A Content Analysis of ECKM Publications”, Electronic Journal of Knowledge Management, 14(1), 2016, pp. 5-17.

[19] Gabriel, Y. and D.S. Griffiths, "Emotion, learning and organizing”, The Learning Organization, 9(5), 2002, pp. 214-221.

[20] Geofroy, Z. de and M.M. Evans, “Are Emotionally Intelligent Employees Less Likely to Hide Their Knowledge?”, Knowledge and Process Management, 24(2), 2017, pp. 81-95.

[21] Glaser, S. and M. Halliday, "Ideology in organisations - a comparison of East and West”, The Learning Organization, 6(3), 1999, pp. 101-107.

[22] Hafner, J.H., "Computer System Unlearning in Individuals", in $48^{\text {th }}$ Hawaii International Conference on System Sciences (HICSS), 2015: 5 - 8 Jan. 2015, Kauai, Hawaii, T.X. Bui and R.H. Sprague, Editors, $201548^{\text {th }}$ Hawaii International Conference on System Sciences (HICSS), HI, USA, 5/1/2015 - 8/1/2015. 2015. IEEE: Piscataway, NJ.

[23] Holland, J., J. Henningsson, U. Johanson, C. Koga, and S. Sakakibara, "Use of IC information in Japanese financial firms”, Journal of Intellectual Capital, 13(4), 2012, pp. 562-581.

[24] Holsapple, C.W. and K.D. Joshi, “A formal knowledge management ontology: Conduct, activities, resources, and influences”, Journal of the American Society for Information Science and Technology, 55(7), 2004, pp. 593-612.

[25] Izard, C.E., “Differential Emotions Theory”, in Human Emotions. 1977. Springer US: Boston, MA.

[26] Izard, C.E., Human emotions, Springer Science \& Business Media, 2013.

[27] Jennex, M. and L. Olfman, “Assessing Knowledge Management Success”, International Journal of Knowledge Management, 1(2), 2005, pp. 33-49.

[28] Jennex, M.E., ed., Knowledge management in modern organizations, Idea Group Publishing, Hershey, Pa., 2007.

[29] Jennex, M.E. and L. Olfman, “A model of knowledge management success”, ME Jennex \& S. Smolnik, eds. Strategies for Knowledge Management Success: Exploring Organizational Efficacy. IGI Global, 2010, pp. 14-31. 
[30] Jennex, M.E., S. Smolnik, and D.T. Croasdell, "Towards a consensus knowledge management success definition”, VINE, 39(2), 2009, pp. 174-188.

[31] Kane, H., G. Ragsdell, and C. Oppenheim, "Knowledge management methodologies", The Electronic Journal of Knowledge Management, 4(2), 2006, pp. 141152.

[32] Kelly, J.R. and S.G. Barsade, "Mood and Emotions in Small Groups and Work Teams”, Organizational Behavior and Human Decision Processes, 86(1), 2001, pp. 99-130.

[33] Lacoste, S.M. and J. Dekker, "Driving change: The role of "emotional connectedness" - a case study", The Learning Organization, 23(5), 2016, pp. 357-369.

[34] Lee, H. and B. Choi, "Knowledge Management Enablers, Processes, and Organizational Performance: An Integrative View and Empirical Examination”, Journal of Management Information Systems, 20(1), 2014, pp. 179228.

[35] Lee, J.-M., G.-W. Bock, and A. Suh, “The Impact of Social Power on transactive Memory Systems and Knowledge Utilization”, in PACIS 2014 Proceedings.

[36] Leeper, R.W., “A motivational theory of emotion to replace 'emotion as disorganized response."”, Psychological Review, 55(1), 1948, pp. 5-21.

[37] Lin, J., H.C. Chan, and K.K. Wei, “The effects of goal orientations on knowledge management system usage, knowledge sourcing and learning outcome”, in ECIS. 2006.

[38] Linden, L.P., "Liberty Support for Singerian Inquiring Systems: Designs from Early American Patriots”, AMCIS 2009 Proceedings, 2009, p. 599.

[39] Malhotra, Y., D.F. Galletta, and L.J. Kirsch, “How Endogenous Motivations Influence User Intentions: Beyond the Dichotomy of Extrinsic and Intrinsic User Motivations”, Journal of Management Information Systems, 25(1), 2008, pp. 267-299.

[40] Mandler, G., Mind and emotion, Krieger Publishing Company, 1975.

[41] Marshall, J., "Expanding the realm of organizational reasoning”, The Learning Organization, 7(5), 2000, pp. 244-251.

[42] Mauss, I.B. and M.D. Robinson, "Measures of emotion: A review”, Cognition \& Emotion, 23(2), 2009, pp. 209-237.

[43] Mowrer, O.H., Learning theory and behavior, John Wiley \& Sons Inc, Hoboken, NJ, US, 1960.

[44] Newell, S., S. Adams, M. Crary, P. Glidden, V. LaFarge, and A. Nurick, “An Autoethnographic Account of Knowledge Creation: Seeing and Feeling Knowledge Creation in Project Teams”, in Proceedings of the $39^{\text {th }}$ Annual Hawaii International Conference on System Sciences: 4 - 7 January 2006, Kauai, Hawaii, R.H. Sprague, Editor, Proceedings of the $39^{\text {th }}$ Annual Hawaii International Conference on System Sciences (HICSS’06), Kauia, HI,
USA, 4/1/2006 - 7/1/2006. 2006. IEEE Computer Society: Los Alamitos, Calif.

[45] Nonaka, I., “A dynamic theory of organizational knowledge creation”, Organization science, 5(1), 1994, pp. 14-37.

[46] Norman, D., "Introduction to This Special Section on Beauty, Goodness, and Usability”, Human-Computer Interaction, 19(4), 2004, pp. 311-318.

[47] Öztel, H. and O. Hinz, "Changing organisations with metaphors”, The Learning Organization, 8(4), 2001, pp. 153-168.

[48] Pemberton, J., S. Mavin, and B. Stalker, "Scratching beneath the surface of communities of (mal)practice", The Learning Organization, 14(1), 2007, pp. 62-73.

[49] Peng, H., "Why and when do people hide knowledge?”, Journal of Knowledge Management, 17(3), 2013, pp. 398-415.

[50] Petrides, K.V. and A. Furnham, “Trait emotional intelligence: Psychometric investigation with reference to established trait taxonomies”, European Journal of Personality, 15(6), 2001, pp. 425-448.

[51] Plutchik, R., A general psychoevolutionary theory of emotion, Academic Press, New York, 1980.

[52] Plutchik, R., "Emotions: A general psychoevolutionary theory”, Approaches to emotion, 1984, pp. 197-219.

[53] Polanyi, M., The Tacit Dimension, London: Routledge and Kegan Paul, London, 1967.

[54] Prusak, L., "Where did knowledge management come from?”, IBM Systems Journal, 40(4), 2001, pp. 1002-1007.

[55] Reus, T.H. and Y. Liu, "Rhyme and Reason: Emotional Capability and the Performance of KnowledgeIntensive Work Groups”, Human Performance, 17(2), 2004, pp. 245-266.

[56] Richards, D., "Playing the party game: Musical careers”, The Learning Organization, 17(2), 2010, pp. 124132.

[57] Sackmann, S.A. and M. Friesl, "Exploring cultural impacts on knowledge sharing behavior in project teams results from a simulation study", Journal of Knowledge Management, 11(6), 2007, pp. 142-156.

[58] Salovey, P. and J.D. Mayer, "Emotional Intelligence”, Imagination, Cognition and Personality, 9(3), 1990, pp. 185-211.

[59] Schacter, D.L., D.T. Gilbert, and D.M. Wegner, "Psychology (2 ${ }^{\text {nd }}$ Edition)", Worth, 2011.

[60] Scherer, K.R., "What are emotions? And how can they be measured?”, Social Science Information, 44(4), 2005, pp. 695-729. 
[61] Scherer, K.R. and V. Tran, "Effects of Emotion on the Process of Organizational Learning”, Handbook of organizational learning and knowledge, 2003, p. 369.

[62] Schiuma, G. and A. Lerro, "Managing knowledge assets in a complex business landscape: The relevance of emotive knowledge”, Knowledge Management Research \& Practice, 9(4), 2011, pp. 279-285.

[63] Schwartz, D.G., “The Emerging Discipline of Knowledge Management”, International Journal of Knowledge Management, 1(2), 2005, pp. 1-11.

[64] Selten, R., “Bounded Rationality”, Journal of Institutional and Theoretical Economics (JITE), 146(4), 1990, pp. 649-658.

[65] Serenko, A. and N. Bontis, “Global ranking of knowledge management and intellectual capital academic journals: 2013 update”, Journal of Knowledge Management, 17(2), 2013, pp. 307-326.

[66] Serenko, A., N. Bontis, L. Booker, K. Sadeddin, and T. Hardie, "A scientometric analysis of knowledge management and intellectual capital academic literature (1994-2008)”, Journal of Knowledge Management, 14(1), 2010, pp. 3-23.

[67] Smith, P.A., "Implications of complexity and chaos theories for organizations that learn”, The Learning Organization, 10(6), 2003, pp. 321-324.

[68] Song, S. and J.T. Teng, "An Exploratory Examination of Knowledge Sharing Behaviors: Voluntary vs. Solicited”, in Proceedings of the $41^{\text {st }}$ Annual Hawaii International Conference on System Sciences (HICSS 2008), 2008 The $41^{\text {st }}$ Annual Hawaii International Conference on System Sciences, Waikoloa, HI, USA, 7/1/2008 - 10/1/2008. 2008. IEEE.

[69] Stacey, R.D., Complex responsive processes in organizations: Learning and knowledge creation, Routledge, London and New York, 2001.

[70] Swift, P.E. and A. Hwang, “The impact of affective and cognitive trust on knowledge sharing and organizational learning”, The Learning Organization, 20(1), 2013, pp. 20-37.
[71] Tenório, N., A. Ferrarezi Vidotti, M. Alaranta, and H.K. Fulk, "The Influence of Positive Emotions on Knowledge Sharing”, AMCIS 2017 Proceedings, 2017, pp. 1-5.

[72] Timbrell, G.T., P. Delaney, T. Chan, W.A. Yue, and G. Gable, "A structurationist review of knowledge management theories”, in ICIS 2005 Proceedings.

[73] Tran, V., "The role of the emotional climate in learning organisations”, The Learning Organization, 5(2), 1998, pp. 99-103.

[74] Trenck, A.v.d., F. Emamjome, T. Neben, and A. Heinzl, "What's in it for Me? Conceptualizing the Perceived Value of Knowledge Sharing”, in $48^{\text {th }}$ Hawaii International Conference on System Sciences (HICSS), 2015: 5 - 8 Jan. 2015, Kauai, Hawaii, T.X. Bui and R.H. Sprague, Editors, $201548^{\text {th }}$ Hawaii International Conference on System Sciences (HICSS), HI, USA, 5/1/2015 - 8/1/2015. 2015. IEEE: Piscataway, NJ.

[75] Trong Tuan, L., "Leading to learning and competitive intelligence”, The Learning Organization, 20(3), 2013, pp. 216-239.

[76] Tuan, L.T., “The chain effect from human resourcebased clinical governance through emotional intelligence and CSR to knowledge sharing”, Knowledge Management Research \& Practice, 14(1), 2016, pp. 126-143.

[77] Urbach, N., S. Smolnik, and G. Riempp, “An empirical investigation of employee portal success", The Journal of Strategic Information Systems, 19(3), 2010, pp. 184-206.

[78] van den Hooff, B., A.P. Schouten, and S. Simonovski, "What one feels and what one knows: The influence of emotions on attitudes and intentions towards knowledge sharing”, Journal of Knowledge Management, 16(1), 2012, pp. 148-158.

[79] Webster, J. and R.T. Watson, “Analyzing the past to prepare for the future: Writing a literature review”, MIS Quarterly, 2002, pp. xiii-xxiii. 